\title{
The Effect of Irradiance on the Degree of Conversion and Volumetric Polymerization Shrinkage of Different Bulk-Fill Resin-Based Composites: An In Vitro Study
}

\author{
${ }^{1}$ Department of Restorative Dental Sciences, College of Dentistry, \\ King Saud University, Riyadh, Kingdom of Saudi Arabia
}

Abrar N. Bin Nooh ${ }^{1} \quad$ Hend Al Nahedh ${ }^{1} \quad$ Mohammad AlRefeai ${ }^{1} \quad$ Fahad Alkhudhairy ${ }^{1, \odot}$

\begin{abstract}
Address for correspondence Abrar N. Bin Nooh, BDS, Department of Restorative Dental Sciences, College of Dentistry, King Saud University, PO Box 60169, Riyadh 11545, Kingdom of Saudi Arabia (e-mail: abrar.nasser@hotmail.com).
\end{abstract}

Eur J Dent 2021;15:312-319

\begin{abstract}
Objective The influence of different light-emitting diode (LED) curing light intensities on the degree of conversion (DC) and volumetric polymerization shrinkage (VPS) of bulk-fill resin-based composite (RBC) restorative materials was evaluated.

Materials and Methods Twenty-four specimens of each RBC material (Filtek one bulk-fill posterior, Reveal HD Bulk, Tetric N-Ceram, and Filtek Z350) were prepared. The RBCs were shaped in molds and cured using an LED curing light unit at high-intensity $\left(1,200 \mathrm{~mW} / \mathrm{cm}^{2}\right)$ for 20 seconds and low-intensity $\left(650 \mathrm{~mW} / \mathrm{cm}^{2}\right)$ for 40 seconds Fourier-transform infrared (FTIR) spectroscopy was used to determine the

Keywords

- curing light intensity

- bulk-fill resin-based composites

- photopolymerization

- FTIR spectroscopy

- degree of conversion

- volumetric polymerization shrinkage DC and microcomputed tomography was used to evaluate VPS. Data were analyzed using one- and two-way ANOVA, independent $t$-test, and Tukey's and Scheffe's post hoc multiple comparison tests.

Results With high-intensity curing light, Reveal HD showed the highest DC $(85.689 \pm 6.811 \%)$ and Tetric $\mathrm{N}$-Ceram the lowest $(52.60 \pm 9.38 \%)$. There was no statistical difference in VPS when using high- or low-intensity curing light. The highest VPS was observed for Reveal HD (2.834-3.193\%); there was no statistical difference $(p>0.05)$ among the other RBCs.

Conclusion Curing light intensities do not significantly influence the VPS of RBC materials. Reveal HD bulk cured with high-intensity light had the highest DC.
\end{abstract}

\section{Introduction}

Dental curing light units used to polymerize restorative materials revolutionized modern dentistry. Different light sources (e.g., light emitting diodes [LEDs] and tungsten halogen) are available for photopolymerization in dentistry applications that require light sources that are safe, efficient, promote fast curing, and compatible with dental materials. Resin-based composite (RBC) materials are now widely used as restorative materials due to increasing esthetic demands. The RBCs are composed of organic resin monomers, inorganic fillers, photoinitiators, and silane coupling agents to bind the fillers to the matrix. Bisphenol A-glycidyl methacrylate (Bis-GMA) has historically been used as the base monomer in commercial dental composites, though other dimethacrylates (e.g., triethylene glycol dimethacrylate [TEGDMA]) have been added due to its high viscosity. ${ }^{1}$ published online

December 15, 2020
DOI https://doi.org/

$10.1055 / \mathrm{s}-0040-1721236$

ISSN 1305-7456. (c) 2020. European Journal of Dentistry.

This is an open access article published by Thieme under the terms of the Creative Commons Attribution License, permitting unrestricted use, distribution, and reproduction so long as the original work is properly cited. (https:// creativecommons.org/licenses/by/4.0/)

Thieme Medical and Scientific Publishers Pvt. Ltd., A-12, 2nd Floor, Sector 2, Noida-201301 UP, India 
Photoinitiators in RBCs trigger polymerization, with the most common photoinitiator system being camphorquinone (CQ), which is accelerated by a tertiary amine. Some commercial formulations include alternative photoinitiators (e.g., Ivocerin in Tetric N-Ceram) that are more color stable and less yellow than CQ. ${ }^{1,2}$ Attempts by manufacturers to improve RBCs have simplified and facilitated rapid placement of large restorations, known as bulk-fill RBCs. These bulk-fill composites provide sufficient polymerization with a 4-mm bulk placement in a single layer. In addition, manufacturers employ a variety of methods to increase the depth of cure (DOC) of bulk-fill RBCs, such as increasing the filler particles size, reducing the filler content, and using an additional photoinitiator. $^{2}$

The degree of conversion (DC) is an important indication of the mechanical performance of RBCs, as adequate polymerization results in enhanced mechanical and physical properties., ${ }^{3,4}$ During photopolymerization, monomers are transformed into complex polymer chains, although not all monomers will be converted into polymer structures, resulting in some unreacted monomers remaining. The polymerization process begins with light absorption in a specific wavelength range by the RBC; the activation process and reaction occurs with the aliphatic amine present in the composite to produce free radicals. The carbon-carbon double bonds present in the monomers are converted into single bonds upon polymer chain formation during the process of polymerization, and this percentage of carbon-carbon double bond to single bond conversion is referred to as the DC (\%). ${ }^{5}$

Multiple techniques are used to measure the DC, including indirect methods such as microhardness testing using Knoop or Vickers indenters, ${ }^{6}$ or by employing a scraping method. However, it has been noted that these techniques overestimate the DOC values, and they also suffer from being difficult to standardize.,8 Vibrational spectroscopy is a direct method for measuring unreacted carbon-carbon double bond and converted single bond percentages in cured materials. While Fourier-transform infrared (FTIR) spectroscopy based on light absorption or Raman spectroscopy based on light scattering can be used, ${ }^{9}$ FTIR spectroscopy is the most common technique employed, as it provides reliable results when measuring the DC. ${ }^{10}$

Volumetric polymerization shrinkage (VPS) is one major disadvantage of RBC restorations. Carbon monomers form polymer chains during light irradiation, resulting in 2 to 3 vol\% shrinkage. ${ }^{11}$ This VPS can lead to inner stresses generated at the resin-tooth interface and cause pain, loss of marginal sealing due to interfacial gaps, and microleakage, which may evolve secondary caries and lead to restoration failure. ${ }^{12}$ Many factors can lead to VPS of RBC materials, such as filler load, filler particles, monomer system, photoinitiators, and light-curing units. The resin matrix composition and filler content determine the extent of VPS. ${ }^{13}$

Several methods and devices have been utilized to measure polymerization shrinkage in terms of linear and volumetric shrinkage and cuspal displacements. Indirect techniques such as finite element analysis, microleakage assessment, and three-dimensional (3D) micro-computed tomography ( $\mu-\mathrm{CT}$ ) have been used. The $\mu-\mathrm{CT}$ method is a nondestructive technique that results in a $3 \mathrm{D}$ image $^{14}$ that has been effectively employed in the assessment of real volumetric shrinkage of RBCs. ${ }^{15}$

With the development of light-curing devices, dentists can cure composites faster by increasing the light intensity to reduce the exposure time, as justified by the Bunsen-Roscoe law (BRL) of reciprocity, ${ }^{16}$ although there are many debates in the literature concerning the validity of BRL. Currently, it is generally agreed that RBC materials require exposure to the radiation of particular wavelengths for a specific duration of time to yield acceptable results. ${ }^{17}$

The aim of this study was to evaluate the effects of different LED curing light intensities on the DC and VPS of bulk-fill $\mathrm{RBC}$ restorative materials. The hypothesis tested was that no statistically significant effect on the DC and VPS of different bulk-fill RBCs would occur from applying curing light at different intensities.

\section{Materials and Methods}

\section{Specimen Preparation}

A total of 96 specimens consisting of 24 disc-shaped specimens of each Filtek one bulk-fill posterior, Reveal HD Bulk, Tetric N-Ceram, and Filtek Z350 (control group) RBC material were fabricated, and shade A2 was selected for all the composites except for Tetric N-Ceram, in which shade IVA was used (the material compositions and manufacturers are listed in - Table 1). Each set of specimens was divided into four groups: two groups were used to measure the DC and the other two groups were used to measure the VPS. Curing with a Bluephase $\mathrm{N}$ light-curing unit was investigated at two intensities: high-intensity output $\left(1,200 \mathrm{~mW} / \mathrm{cm}^{2}\right)$ for 20 seconds and low-intensity output $\left(650 \mathrm{~mW} / \mathrm{cm}^{2}\right)$ for 40 seconds. The power intensity was measured using a dental Bluephase radiometer (Ivoclar Vivadent). For each group, six specimens were used to measure DC and VPS at each curing light intensity.

A special custom Teflon mold for the VPS samples and a two-part brass mold for DC samples (10 mm diameter and $4 \mathrm{~mm}$ depth) were used for Filtek one bulk-fill posterior, Reveal HD Bulk, and Tetric N-Ceram measurements, and different size molds (10 $\mathrm{mm}$ diameter, $2 \mathrm{~mm}$ depth) were used for the Filtek Z350 control group. After the materials were placed in the molds, a clear Mylar strip (Mylar Unistrip, Caulk/Dentsply, Milford, Delaware, United States) and a 1-mm thick glass plate were secured over each mold to flatten the surface and then gently pressed to remove excess material on the mold.

\section{Degree of Conversion}

Twelve samples of each RBC were prepared for DC measurements. The mold was placed on a dark nonreflective surface for measurements before and after polymerization. The absorbance and transmission peaks were obtained using the reflectance mode of the FTIR spectrometer (Thermo Scientific, NICOLET iS10, United States). The DC (\%) were 
Table 1 Composition of the materials tested as provided by the manufacturer

\begin{tabular}{|c|c|c|}
\hline Material & Manufacturer & Composition \\
\hline $\begin{array}{l}\text { Filtek } \\
\text { one } \\
\text { bulk-fill } \\
\text { posterior }\end{array}$ & 3M ESPE & $\begin{array}{l}\text { Monomer matrix: AUDMA, } \\
\text { addition-fragmentation } \\
\text { monomer (dynamic } \\
\text { stress-relieving monomer), } \\
\text { 1,12-diaminododecane } \\
\text { (dimethacrylate), and UDMA } \\
\text { Fillers: a combination of a non- } \\
\text { agglomerated/nonaggregated } \\
20 \mathrm{~nm} \text { silica filler, a } \\
\text { nonagglomerated/nonaggregated } \\
4 \text { to } 11 \text { nm zirconia filler, an } \\
\text { aggregated zirconia/silica cluster } \\
\text { filler (comprised of } 20 \text { nm silica } \\
\text { and } 4 \text { to } 11 \text { nm zirconia particles), } \\
\text { and an ytterbium trifluoride filler } \\
\text { consisting of agglomerate } 100 \mathrm{~nm} \\
\text { particles. The inorganic filler } \\
\text { loading is } 76.5 \text { wt\% (58.4 vol\%) }\end{array}$ \\
\hline $\begin{array}{l}\text { Reveal } \\
\text { HD } \\
\text { Bulk Fill }\end{array}$ & BISCO & $\begin{array}{l}\text { Monomer matrix: UDMA and } \\
\text { BisGMA } \\
\text { Filler: ytterbium fluoride }\end{array}$ \\
\hline $\begin{array}{l}\text { Tetric } \\
\mathrm{N} \text {-Ceram }\end{array}$ & $\begin{array}{l}\text { Ivoclar } \\
\text { Vivadent, } \\
\text { Schaan, } \\
\text { Liechtenstein }\end{array}$ & $\begin{array}{l}\text { Monomer matrix: } \\
\text { dimethacrylates. } \\
\text { Filler: barium glass, ytterbium } \\
\text { trifluoride pre-polymer, and mixed } \\
\text { oxides. Filler content is } 75 \text { to } \\
77 \text { wt\% (53-55 vol\%) }\end{array}$ \\
\hline $\begin{array}{l}\text { Filtek } \\
\text { Z350 XT } \\
\text { (control) }\end{array}$ & 3M ESPE & $\begin{array}{l}\text { Monomer matrix: Bis-GMA, } \\
\text { UDMA, TEGDMA, and bis-EMA. } \\
\text { Filler: Combination of } \\
\text { nonagglomerated/nonaggregated } \\
20 \text { nm silica filler, nonagglomerated/ } \\
\text { nonaggregated } 4 \text { to } 11 \mathrm{~nm} \\
\text { zirconia filler, and aggregated } \\
\text { zirconia/silica cluster filler } \\
\text { (comprised of } 20 \text { nm silica } \\
\text { and } 4-11 \mathrm{~nm} \text { zirconia particles). } \\
\text { The inorganic filler loading is } \\
\sim 72.5 \text { wt\% (55.6 vol\%) }\end{array}$ \\
\hline
\end{tabular}

Abbreviations: AUDMA, aromatic urethane dimethacrylate; BisGMA, bisphenol A-glycidyl methacrylate; UDMA, urethane dimethacrylate.

determined from the ratio of the absorbance intensities of the aliphatic $C=C$ peak $\left(1,638 \mathrm{~cm}^{-1}\right)$ against the internal reference aromatic $C=C$ peak $\left(1,608 \mathrm{~cm}^{-1}\right)$. The $D C$ was determined according to the following equation:

$$
\text { DC\% conversion }=\left(1-\frac{\left(1638 \mathrm{~cm}^{-1} / 1608 \mathrm{~cm}^{-1}\right. \text { cured }}{\left(1638 \mathrm{~cm}^{-1} / 1608 \mathrm{~cm}^{-1}\right. \text { uncured }}\right) \times 100
$$

\section{Micro-Computed Tomography Analysis}

Twelve samples were prepared from each composite. The mold was positioned inside the $\mu$-CT chamber, and each sample was scanned for 1 hour pre- and postpolymerization using a high-resolution 3D X-ray microscope (Bruker SkyScan 1172, Kontich, Belgium). The $\mu-\mathrm{CT}$ projection images were acquired with $88 \mathrm{kV}$ voltage, $114 \mu \mathrm{A}$ anode current, 316 milliseconds exposure time, $15.89 \mu \mathrm{m}$ image pixel size, $\mathrm{Al}+\mathrm{Cu}$ filter, 0.4 rotation step for 360 degrees, frame averaging of four for improved signal-to-noise ratio, and eight random movements to minimize ring artifacts. A flat-field correction was performed before the scanning procedure to account for variations in camera pixel sensitivity.

The $\mu$-CT data were evaluated with DataViewer software (version 1.5.6.2, Bruker SkyScan, Kontich, Belgium) after image reconstruction. The pre- and postpolymerization scans were analyzed using the $3 \mathrm{D}$ analysis tool to give a volume output value using CTAn software (Bruker Skyscan, Kontich, Belgium). Finally, CTVol software (version 2.3.2.0, Bruker SkyScan, Kontich, Belgium) was used for 3D visualization and production of color-coded images of the samples.

\section{Statistical Analysis}

Data are expressed as the mean and standard deviation determined using SPSS Statistics software (version 22.0; IBM SPSS, Armonk, New York, United States). The results were first tested for normality using the Shapiro-Wilk test. The results were then analyzed using two-way analysis of variance (ANOVA) followed by independent $t$-test and one-way ANOVA. Comparisons between the individual groups were made with Tukey's or Scheffe's post hoc test to determine the significant differences between the materials and curing light intensities. All tests were performed at a significance level of $p<0.05$.

\section{Results}

\section{Degree of Conversion}

A significant effect associated with curing light intensity $(\mathrm{F}=6.09, p<0.01)$ and type of $\mathrm{RBC}(\mathrm{F}=22.05, p<0.000)$ was observed when determining the DC ( - Table 2 for the two-way ANOVA test results). However, the interaction of RBC and curing light intensity was not significant $(\mathrm{F}=1.07, p<0.37$ ) (one-way ANOVA results of the materials for each light-cure intensity are listed in - Table 3). When applying high-intensity curing light, the DC of Reveal HD Bulk was the highest (85.689 $\pm 6.811 \%)$, followed by Filtek One (74.92 \pm 3.58\%), Filtek Z350 (69.15 \pm $10.86 \%)$, and Tetric N-Ceram (55.561 $\pm 4.898 \%)$. There was a significant difference between one of the material F-test with $p<0.00$. To identify the material, we did the multiple comparison test (Tukey) which showed that Reveal HD Bulk with $85.689 \pm 6.811 \%$ DC was more significant than Filtek Z350 with $69.152 \pm 10.865 \%$ DC at $p<0.003$ and Tetric N-Ceram with $55.561 \pm 4.898 \%$ DC at $p<0.00$. Tetric N-Ceram exhibited significantly less DC than Filtek one bulk fill posterior at $p<0.001$ and Filtek Z350 at $p<0.017$.

Application of low-intensity curing light resulted in Reveal HD bulk fill again having the highest DC (72.91 $\pm 3.69 \%)$ among all the RBCs, followed by Filtek one bulk fill posterior (71.41 $\pm 5.50 \%)$, Filtek Z350 (65.74 $\pm 13.07 \%)$, and Tetric $\mathrm{N}$-Ceram (52.60 $\pm 9.38 \%$ ). Tetric N-Ceram was significantly different from Reveal HD bulk fill at $\mathrm{p}<0.003$ and Filtek One at $\mathrm{p}<0.006$. The effect of curing light intensity for each material is listed in - Table 4 . It is clear that the only material that exhibits a significant difference when using different curing light intensities is Reveal HD bulk fill. With high-intensity curing light, Reveal HD exhibited a greater 
Table 2 Two-way analysis of variance

\begin{tabular}{|l|l|l|l|l|l|}
\hline Source & $\begin{array}{l}\text { Type III sum of } \\
\text { squares }\end{array}$ & $\mathrm{df}$ & Mean square & F-ratio & $p$-Value \\
\hline Curing light intensity & 384.439 & 1 & 384.439 & 6.099 & 0.018 \\
\hline RBC & 4170.517 & 3 & 1390.172 & 22.054 & 1.072 \\
\hline $\begin{array}{l}\text { Curing light } \\
\text { intensity } \times \text { RBC }\end{array}$ & 202.679 & 3 & 67.560 & 0.372 \\
\hline Error & 2521.374 & 40 & 63.034 & & \\
\hline Total & 232512.488 & 48 & & & \\
\hline Corrected total & 7279.008 & 47 & & & \\
\hline
\end{tabular}

Abbreviations: RBC, resin-based composite.

Table 3 One-way analysis of variance and multiple comparison test (Tukey)

\begin{tabular}{|c|c|c|c|c|c|c|c|c|c|c|}
\hline \multirow[t]{2}{*}{$\begin{array}{l}\text { Curing light } \\
\text { intensity }\end{array}$} & \multirow[t]{2}{*}{$\begin{array}{l}\text { RBC } \\
\text { material }\end{array}$} & \multirow[t]{2}{*}{$\begin{array}{l}\text { Mean } \\
(\%)\end{array}$} & \multirow[t]{2}{*}{ SD } & \multirow[t]{2}{*}{$\begin{array}{l}F \text { test } \\
p \text {-Value }\end{array}$} & \multicolumn{2}{|c|}{$\begin{array}{l}95 \% \text { confidence } \\
\text { interval for mean }\end{array}$} & \multicolumn{4}{|c|}{ Multiple comparison test (Tukey) } \\
\hline & & & & & $\begin{array}{l}\text { Lower } \\
\text { bound }\end{array}$ & $\begin{array}{l}\text { Upper } \\
\text { bound }\end{array}$ & Filtek Z350 & Filtek One & $\begin{array}{l}\text { Tetric } \\
\text { N-Ceram }\end{array}$ & $\begin{array}{l}\text { Reveal } \\
\text { HD }\end{array}$ \\
\hline \multirow[t]{4}{*}{ High } & Filtek Z350 & 69.152 & 10.865 & \multirow[t]{4}{*}{$<0.000$} & 57.750 & 80.553 & 1 & & & \\
\hline & Filtek One & 74.922 & 3.587 & & 71.157 & 78.686 & 0.509 & 1 & & \\
\hline & \begin{tabular}{|l|} 
Tetric \\
N-Ceram
\end{tabular} & 55.561 & 4.898 & & 50.421 & 60.702 & 0.017 & 0.001 & 1 & \\
\hline & Reveal HD & 85.689 & 6.811 & & 78.541 & 92.836 & 0.003 & 0.070 & 0.000 & 1 \\
\hline \multirow[t]{4}{*}{ Low } & Filtek Z350 & 65.746 & 13.077 & \multirow[t]{4}{*}{$<0.002$} & 52.023 & 79.469 & 1 & & & \\
\hline & Filtek One & 71.418 & 5.502 & & 65.644 & 77.191 & 0.677 & 1 & & \\
\hline & $\begin{array}{l}\text { Tetric } \\
\mathrm{N} \text {-Ceram }\end{array}$ & 52.601 & 9.385 & & 42.752 & 62.449 & 0.072 & 0.006 & 1 & \\
\hline & Reveal HD & 72.919 & 3.694 & & 69.042 & 76.796 & 0.498 & 0.990 & 0.003 & 1 \\
\hline
\end{tabular}

Abbreviations: RBC, resin-based composite; SD, standard deviation.

Table 4 Descriptive $t$-test analysis

\begin{tabular}{|c|c|c|c|c|c|c|}
\hline \multirow[t]{2}{*}{$\begin{array}{l}\mathrm{RBC} \\
\text { material }\end{array}$} & \multirow[t]{2}{*}{$\begin{array}{l}\text { Curing light } \\
\text { intensity }\end{array}$} & \multirow[t]{2}{*}{ Mean (\%) } & \multirow[t]{2}{*}{ SD } & \multicolumn{2}{|c|}{$\begin{array}{l}\text { 95\% confidence interval } \\
\text { for mean }\end{array}$} & \multirow[t]{2}{*}{$\begin{array}{l}t \text {-test } \\
p \text {-Value }\end{array}$} \\
\hline & & & & Lower bound & Upper bound & \\
\hline \multirow[t]{2}{*}{ Filtek Z350 } & High & 69.152 & 10.865 & 57.750 & 80.553 & \multirow[t]{2}{*}{0.634} \\
\hline & Low & 65.746 & 13.077 & 52.023 & 79.469 & \\
\hline \multirow[t]{2}{*}{ Filtek One } & High & 74.922 & 3.587 & 71.157 & 78.686 & \multirow[t]{2}{*}{0.220} \\
\hline & Low & 71.418 & 5.502 & 65.644 & 77.191 & \\
\hline \multirow{2}{*}{$\begin{array}{l}\text { Tetric } \\
\mathrm{N} \text {-Ceram }\end{array}$} & High & 55.561 & 4.898 & 50.421 & 60.702 & \multirow[t]{2}{*}{0.509} \\
\hline & Low & 52.601 & 9.385 & 42.752 & 62.449 & \\
\hline \multirow[t]{2}{*}{ Reveal HD } & High & 85.689 & 6.811 & 78.541 & 92.836 & \multirow[t]{2}{*}{0.002} \\
\hline & Low & 72.919 & 3.694 & 69.042 & 76.796 & \\
\hline
\end{tabular}

Abbreviations: RBC, resin-based composite; SD, standard deviation.

DC $(85.689 \pm 6.811 \%)$ compared with when low-intensity curing light was applied (72.919 $\pm 3.694 \% ; p<0.002)$.

\section{Volumetric Polymerization Shrinkage}

VPS was investigated next to determine whether curing light intensity had a significant effect. Two-way ANOVA ( - Table 5) indicates a significant effect associated with the
RBCs $(F=16.41, p<0.000)$, whereas the curing light intensity ( $\mathrm{F}=0.001, p<0.97)$ and the interaction of the curing light with RBCs $(F=1.80, p<0.16)$ is not significant for VPS.

The VPS of RBC materials was compared at low and high intensity; the results of which are listed in - Table 6. When using the high-intensity curing light, Reveal HD Bulk $(3.19 \pm 0.59 \%)$ had the highest VPS among all the 
Table 5 analysis of variance related to volumetric polymerization shrinkage

\begin{tabular}{|l|l|l|l|l|l|}
\hline Source & Type III sum of squares & df & $\begin{array}{l}\text { Mean } \\
\text { square }\end{array}$ & F-ratio & $p$-Value \\
\hline Light cure intensity & 0.000 & 1 & 0.000 & 0.001 & 0.972 \\
\hline RBC & 4.945 & 3 & 1.648 & 16.412 & $<0.000$ \\
\hline Light cure intensity $\times$ RBC & 0.543 & 3 & 0.181 & 1.804 & 0.162 \\
\hline Error & 4.018 & 40 & 0.100 & & \\
\hline Total & 308.303 & 48 & & & \\
\hline Corrected total & 9.506 & 47 & & & \\
\hline
\end{tabular}

Abbreviation: RBC, resin-based composite.

Table 6 One-way analysis of variance and multiple comparison test (Tukey) related to VPS

\begin{tabular}{|c|c|c|c|c|c|c|c|c|c|c|}
\hline \multirow{2}{*}{$\begin{array}{l}\text { Curing Light } \\
\text { Irradiance }\end{array}$} & \multirow[t]{2}{*}{ RBC Material } & \multirow[t]{2}{*}{ Mean } & \multirow{2}{*}{$\begin{array}{l}\text { Std. } \\
\text { Deviation }\end{array}$} & \multirow{2}{*}{$\begin{array}{l}\text { F-test } \\
p \text {-Value }\end{array}$} & \multicolumn{2}{|c|}{ 95\% Confidence Interval for Mean } & \multicolumn{4}{|c|}{ Multiple Comparison Test (Tukey) } \\
\hline & & & & & Lower Bound & Upper bound & Z3xt & FOB & TB & RB \\
\hline & Z3xt & 2.254 & 0.185 & & 2.059 & 2.449 & 1 & & & \\
\hline \multirow{3}{*}{ High intensity } & FOB & $2.098 \%$ & 0.176 & \multirow{3}{*}{$P<0.000$} & 1.913 & 2.282 & 0.863 & 1 & & \\
\hline & TB & $2.429 \%$ & 0.242 & & 2.175 & 2.682 & 0.819 & 0.374 & 1 & \\
\hline & RB & $3.193 \%$ & 0.599 & & 2.565 & 3.821 & 0.001 & 0.000 & 0.006 & 1 \\
\hline \multirow{4}{*}{ Low irradiance } & Z3xt & $2.444 \%$ & 0.352 & \multirow{4}{*}{$P<0.008$} & 2.075 & 2.813 & 1 & & & \\
\hline & FOB & $2.196 \%$ & 0.219 & & 1.966 & 2.426 & 0.446 & 1 & & \\
\hline & TB & $2.512 \%$ & 0.317 & & 2.180 & 2.844 & 0.975 & 0.246 & 1 & \\
\hline & RB & $2.834 \%$ & 0.222 & & 2.601 & 3.068 & 0.113 & 0.005 & 0.233 & 1 \\
\hline
\end{tabular}

materials, followed by Tetric N-Ceram (2.42 $\pm 0.24 \%)$, Filtek Z350 (2.25 $\pm 0.18 \%)$, and Filtek one bulk fill posterior $(2.09 \pm 0.17 \%)$.

There was a significant difference between the materials (F-test $p<0.00$ ) under high-intensity irradiation. The multiple comparison test showed that Reveal HD bulk fill had a significantly higher VPS than Tetric N-Ceram $(p<0.006)$, Filtek Z350 ( $p<0.001)$, and Filtek One Bulk Fill $(p<0.000)$. Comparison of RBCs subjected to low-intensity curing light gave similar results, with Reveal HD again exhibiting the highest VPS $(2.83 \pm 0.22)$, followed by Tetric N-Ceram (2.51 \pm 0.31$)$, Filtek Z350 (2.44 \pm 0.35$)$, and Filtek One Bulk Fill $(2.19 \pm 0.21)$. There was no significant different between the materials, except for Reveal HD and Filtek one bulk fill $(p<0.005)$. The effect of curing light intensity on the VPS for each RBC analyzed with the $t$-test is displayed in - Table 7. The curing light intensity had no significant effect on the VPS for all of the tested materials. Postpolymerization 3D images of the materials are shown in - Fig. 1.

\section{Discussion}

In this study, the DC and VPS of bulk-fill RBCs were evaluated with exposure to two different curing light intensities. The results of this study showed that the curing light intensity had no effect on the VPS and also had no effect on the DC, except for the Reveal HD bulk-fill RBC, in which high-intensity curing light exposure resulted in a high percentage of DC.

FTIR spectroscopy was employed to determine the DC; FTIR is a reliable technique that is frequently used to obtain the DC of carbon-carbon double bonds converted to single bonds. ${ }^{10}$ Several factors can affect the DC such as the chemistry of the organic matrix, the photoinitiator used, and the filler amount, size, and distribution. ${ }^{4}$ A very important factor that also affects the DC is the light source used, ${ }^{18}$ photoactivation method, ${ }^{19}$ wavelength, ${ }^{20}$ light tip size, power density, ${ }^{21}$ and irradiation time. ${ }^{22}$

A significant difference in the DC was observed among the materials tested. A systematic review by Lima et al ${ }^{23}$ evaluated the DOC in bulk-fill RBCs revealing that the polymerization of bulk-fill RBCs depends on both the radiant exposure (irradiance and time) and material composition, recommending curing light with LED irradiance $\geq 1,000 \mathrm{~mW} / \mathrm{cm}^{2}$ with 20 -second exposure time to obtain acceptable DOC of bulkfill RBCs.

Reveal HD bulk-fill RBC exhibited the highest DC (72.9\%) with low-intensity light and $85.6 \%$ DC with high-intensity light irradiation. This can be explained by the Reveal HD filler technology, which utilizes fillers to refract light deeper in the mass of the material, allowing for a higher DOC. The Reveal HD bulk-fill RBC was the only material affected by curing light intensity, whereby higher intensity light irradiation resulted in a higher percentage of DC. Wydra et $\mathrm{al}^{24}$ observed similar DC behavior with a dimethacrylate RBC exposed to high and low irradiance, whereby high-intensity light resulted in a higher DC.

However, Filtek one bulk-fill posterior, FiltekZ350, and Tetric $\mathrm{N}$-Ceram bulk-fill RBCs were not affected by the curing light intensity, which is in agreement with other studies ${ }^{25,26}$ which also showed that the light cure intensity did not affect the DC of bulk-fill composite resins. Hasslen et $\mathrm{al}^{25}$ evaluated the DOC of bulk-fill composites with three different irradiance 
Table 7 Descriptive t-test analysis

\begin{tabular}{|c|c|c|c|c|c|c|}
\hline \multirow{2}{*}{$\begin{array}{l}\mathrm{RBC} \\
\text { material }\end{array}$} & \multirow{2}{*}{$\begin{array}{l}\text { Curing light } \\
\text { intensity }\end{array}$} & \multirow[t]{2}{*}{ Mean (\%) } & \multirow[t]{2}{*}{ SD } & \multicolumn{2}{|c|}{$95 \%$ confidence interval for mean } & \multirow{2}{*}{$\begin{array}{l}t \text {-test } \\
p \text {-Value }\end{array}$} \\
\hline & & & & Lower bound & Upper bound & \\
\hline \multirow[t]{2}{*}{ Filtek Z350 } & High & 2.254 & 0.185 & 2.059 & 2.449 & \multirow[t]{2}{*}{0.269} \\
\hline & Low & 2.444 & 0.352 & 2.075 & 2.813 & \\
\hline \multirow[t]{2}{*}{ Filtek One } & High & 2.098 & 0.176 & 1.913 & 2.282 & \multirow[t]{2}{*}{0.414} \\
\hline & Low & 2.196 & 0.219 & 1.966 & 2.426 & \\
\hline \multirow{2}{*}{$\begin{array}{l}\text { Tetric } \\
\text { N-Ceram }\end{array}$} & High & 2.429 & 0.242 & 2.175 & 2.682 & \multirow[t]{2}{*}{0.619} \\
\hline & Low & 2.512 & 0.317 & 2.180 & 2.844 & \\
\hline \multirow[t]{2}{*}{ Reveal HD } & High & 3.193 & 0.599 & 2.565 & 3.821 & \multirow[t]{2}{*}{0.100} \\
\hline & Low & 2.834 & 0.222 & 2.601 & 3.068 & \\
\hline
\end{tabular}

Abbreviations: RBC, resin-based composite; SD, standard deviation.

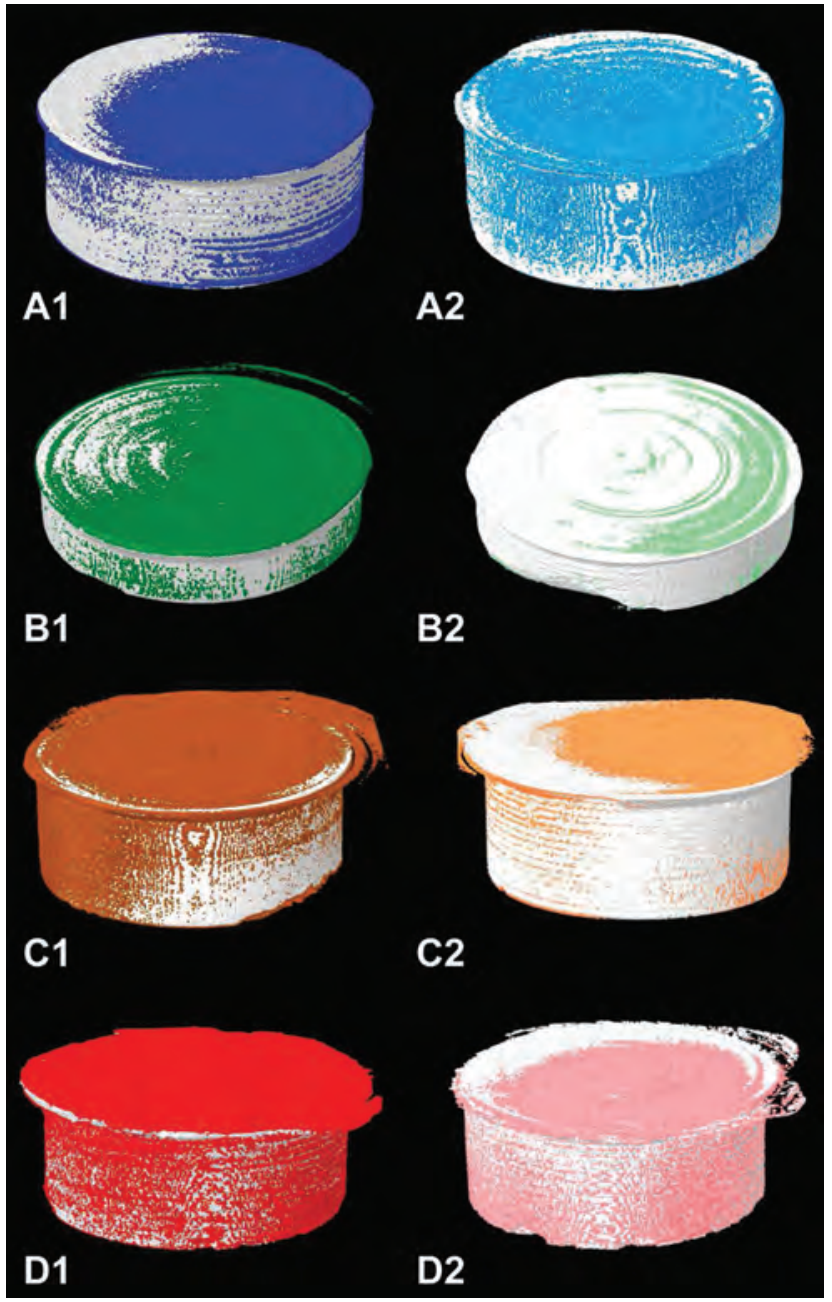

Fig. 1 Images of three-dimensional reconstructions of composite restorations. 1: high-intensity curing light; 2: low-intensity curing light; A: Filtek One Bulk Fill Posterior; B: Filtek Z350; C: Tetric N-Ceram; D: Reveal HD Bulk.

exposures (i.e., standard power mode, $1,000 \mathrm{~mW} / \mathrm{cm}^{2}$; highpower mode, $1,400 \mathrm{~mW} / \mathrm{cm}^{2}$; and Xtra power mode, 3,200 $\mathrm{mW} / \mathrm{cm}^{2}$ ), concluding that the curing light mode did not affect the DOC of the tested bulk-fill materials.

Although an additional photoinitiator (Ivocerin) is added to the Tetric N-Ceram bulk-fill RBC, it resulted in the lowest DC, which is consistent with a previous report that also observed a low DC for this bulk-fill RBC. ${ }^{27}$ The low DC of Tetric N-Ceram could be due to differences in the material composition. The two main monomer characteristics that affect the DC are the initial monomer viscosity and chemical structure flexibility. ${ }^{28}$ Bis-GMA is the least flexible and most viscous monomer among the monomers in this study, which is due to the presence of rigid aromatic groups that interact and strong hydrogen bonding of the hydroxyl groups present in the monomer. UDMA possesses lower viscosity and higher flexibility compared with Bis-GMA due to weak hydrogen bonding of its amine group compared with that of the hydroxyl groups. ${ }^{29}$

In the present study, the Reveal HD Bulk RBC had the highest VPS and highest DC compared with the rest of the tested composites. This can be explained by the direct relationship between VPS and DC. ${ }^{30}$ Filtek one bulk-fill posterior had the least VPS, which the manufacturer claims arises from the innovative aromatic urethane dimethacrylate and addition-fragmentation monomer present in the formulation, which reduce shrinkage and relieve stress during polymerization.

Filtek Z350 was used in the study as a conventional RBC to act as a control, ultimately exhibiting no significant difference in the VPS compared with the bulk-fill RBCs. This was in agreement with a study by Abbasi et al, ${ }^{31}$ whereby no significant difference was observed between the conventional and bulk-fill RBC in terms of VPS. Another study by Rizzante et al $^{32}$ examined the VPS of bulk-fill composites using $\mu-C T$ concluding that the bulk-fill RBCs provided similar results to the conventional RBC.

Curing light intensity did not affect the VPS in the current study, similar to what Sampaio et al observed, noting also that what mostly affects the VPS are the material compositions. ${ }^{33}$ In a randomized clinical study, the effectiveness of using high-intensity LED curing light on the clinical performance of bulk-fill RBC restorations was evaluated; no difference in performance was observed between the conventionally used intensity and high-intensity light used for curing the restorations. ${ }^{34}$ All of the tested RBCs in this study had a VPS ranging from 2.090 to $3.193 \%$, which is an acceptable value. ${ }^{35}$ Furthermore, the use of high-intensity curing light for 20 seconds or low-intensity curing light for 40 seconds had no significant effect on the VPS. 


\section{Conclusion}

Different curing light intensities did not significantly influence VPS in all of the RBC materials tested. The Reveal HD bulk-fill composite cured under high-intensity light exhibited the highest DC. Light intensity had no effect on the DC for the rest of the materials. The hypothesis in this study was partially accepted, since there was no statistically significant effect on VPS when different curing light intensities were used. However, curing light intensity did affect the DC of one material, Reveal HD bulk fill, which had a higher DC when using high-intensity curing light. The results of this study can aid dentists to optimize the clinical performance of restorations. However, more longitudinal clinical studies are needed to support the use of bulk-fill RBCs in clinical practice.

\section{Funding \\ None.}

\section{Conflict of Interest}

None declared.

\section{Acknowledgments}

The present study was registered at and approved by the College of Dentistry Research Center (registration number: PR 0091). This manuscript is a part of a dissertation for DScD.

\section{References}

1 Stansbury JW. Curing dental resins and composites by photopolymerization. J Esthet Dent 2000;12(6):300-308

2 Ilie N, Bucuta S, Draenert M. Bulk-fill resin-based composites: an in vitro assessment of their mechanical performance. Oper Dent 2013;38(6):618-625

3 Lempel E, Czibulya Z, Kunsági-Máté S, et al. Quantification of conversion degree and monomer elution from dental composite using HPLC and micro-Raman spectroscopy. Chromatographia 2014;77:1137-1144

4 Alshali RZ, Silikas N, Satterthwaite JD. Degree of conversion of bulk-fill compared to conventional resin-composites at two time intervals. Dent Mater 2013;29(9):e213-e217

5 Noronha Filho JD, Brandão NL, Poskus LT, Guimarães JG, Silva EM. A critical analysis of the degree of conversion of resin-based luting cements.J Appl Oral Sci 2010;18(5):442-446

6 Rueggeberg FA, Ergle JW, Mettenburg DJ. Polymerization depths of contemporary light-curing units using microhardness. J Esthet Dent 2000;12(6):340-349

7 Leprince JG, Leveque P, Nysten B, Gallez B, Devaux J, Leloup G. New insight into the "depth of cure" of dimethacrylate-based dental composites. Dent Mater 2012;28(5):512-520

8 Flury S, Hayoz S, Peutzfeldt A, Hüsler J, Lussi A. Depth of cure of resin composites: is the ISO 4049 method suitable for bulk fill materials? Dent Mater 2012;28(5):521-528

9 Pianelli C, Devaux J, Bebelman S, Leloup G. The micro-Raman spectroscopy, a useful tool to determine the degree of conversion of light-activated composite resins. J Biomed Mater Res 1999;48(5):675-681

10 de la Macorra JC, Pérez-Higueras JJ. Microtensile bond strength test bias caused by variations in bonded areas. J Adhes Dent 2014;16(3):207-219

11 Burgess J, Cakir D. Comparative properties of low-shrinkage composite resins. Compend Contin Educ Dent 2010;31(Spec No 2):10-15
12 Ferracane JL, Hilton TJ. Polymerization stress: is it clinically meaningful? Dent Mater 2016;32(1):1-10

13 Kleverlaan CJ, Feilzer AJ. Polymerization shrinkage and contraction stress of dental resin composites. Dent Mater 2005; 21(12):1150-1157

14 Atria PJ, Sampaio CS, Cáceres E, et al. Micro-computed tomography evaluation of volumetric polymerization shrinkage and degree of conversion of composites cured by various light power outputs. Dent Mater J 2018;37(1):33-39

15 Sampaio CS, Atria PJ, Rueggeberg FA, et al. Effect of blue and violet light on polymerization shrinkage vectors of a CQ/ TPO-containing composite. Dent Mater 2017;33(7):796-804

16 Bunsen RW, Roscoe HE. Photochemical studies. Ann Phys 1923;108:193

17 Roulet J-F, Price R. Light curing - guidelines for practitioners - a consensus statement from the 2014 symposium on light curing in dentistry held at Dalhousie University, Halifax, Canada. J Adhes Dent 2014;16(4):303-304

18 Galvão MR, Costa SX, Victorino KR, et al. Influence of light guide tip used in the photo-activation on degree of conversion and hardness of one nanofilled dental composite. Laser Phys 2010;20:2050-2055

19 Sgarbi SC, Pereira SK, Martins JMH, et al. Degree of conversion of resin composites light activated by halogen light and led analyzed by ultraviolet spectrometry. Rev Clín Pesq Odontol Curitiba 2010;6:223-230

20 Cekic-Nagas I, Egilmez F, Ergun G. The effect of irradiation distance on microhardness of resin composites cured with different light curing units. Eur J Dent 2010;4(4):440-446

21 Galvão MR, Caldas SGFR, Bagnato VS, de Souza Rastelli AN, de Andrade MF. Evaluation of degree of conversion and hardness of dental composites photo-activated with different light guide tips. Eur J Dent 2013;7(1):86-93

22 Yoshikawa T, Morigami M, Sadr A, Tagami J. Acceleration of curing of resin composite at the bottom surface using slow-start curing methods. Dent Mater J 2013;32(6):999-1004

23 Lima RBW, Troconis CC, Moreno MBP, Murillo-Gómez F, De Goes MF. Depth of cure of bulk fill resin composites: a systematic review. J Esthet Restor Dent 2018;30(6):492-501

24 Wydra JW, Cramer NB, Stansbury JW, Bowman CN. The reciprocity law concerning light dose relationships applied to BisGMA/ TEGDMA photopolymers: theoretical analysis and experimental characterization. Dent Mater 2014;30(6):605-612

25 Hasslen JA, Barkmeier WW, Shaddy RS, Little JR. Depth of cure of high-viscosity bulk-fill and conventional resin composites using varying irradiance exposures with a light-emitting diode curing unit. J Oral Sci 2019;61(3):425-430

26 Majidinia S, Bagheri H, Ramezani S, et al. Polymerization shrinkage, shrinkage stress, and degree of conversion in bulk-fill resin composites after different photo-activation methods. Dent Hypotheses 2020;11:4-10

27 Jain L, Mehta D, Meena N, Gupta R. Influence of light energy density, composite type, composite thickness, and postcuring phase on degree of conversion of bulk-fill composites. Contemp Clin Dent 2018;9(Suppl 1) :S147-S152

28 Dickens SH, Stansbury JW, Choi KM, Floyd CJE. Photopolymerization kinetics of methacrylate dental resins. Macromolecules 2003;36:6043-6053

29 Khatri CA, Stansbury JW, Schultheisz CR, Antonucci JM. Synthesis, characterization and evaluation of urethane derivatives of Bis-GMA. Dent Mater 2003;19(7):584-588

30 Gonçalves F, Boaro LCC, Miyazaki CL, Kawano Y, Braga RR. Influence of polymeric matrix on the physical and chemical properties of experimental composites. Braz Oral Res 2015;29(1):S1806-83242015000100307

31 Abbasi M, Moradi Z, Mirzaei M, Kharazifard MJ, Rezaei S. Polymerization shrinkage of five bulk-fill composite resins 
in comparison with a conventional composite resin. J Dent (Tehran) 2018;15(6):365-374

32 Rizzante FAP, Duque JA, Duarte MAH, Mondelli RFL, Mendonça G, Ishikiriama SK. Polymerization shrinkage, microhardness and depth of cure of bulk fill resin composites. Dent Mater J 2019;38(3):403-410

33 Sampaio CS, Pizarro PG, Atria PJ, Hirata R, Giannini M, Mahn E. Effect of shortened light-curing modes on bulk-fill resin composites. Oper Dent 2020
34 Fahim SE, Mostafa MA, Abi-Elhassan MH, Taher HM. Clinical behaviour and marginal sealing of bulk-fill resin composite restorations using light amplified high-intensity LEDs curing: a randomized controlled clinical trial. Open Access Maced J Med Sci 2019;7(8):1360-1368

35 Ferracane JL. Developing a more complete understanding of stresses produced in dental composites during polymerization. Dent Mater 2005;21(1):36-42 